\title{
Domesticated dogs' (Canis familiaris) use of the solidity principle
}

\author{
Shannon M. A. Kundey • Andres De Los Reyes • \\ Chelsea Taglang $\cdot$ Ayelet Baruch $\cdot$ Rebecca German
}

Received: 26 May 2009 / Revised: 25 November 2009 / Accepted: 26 November 2009 / Published online: 20 December 2009

(C) Springer-Verlag 2009

\begin{abstract}
Organisms must often make predictions about the trajectories of moving objects. However, often these objects become hidden. To later locate such objects, the organism must maintain a representation of the object in memory and generate an expectation about where it will later appear. We explored adult dogs' knowledge and use of the solidity principle (that one solid object cannot pass through another solid object) by evaluating search behavior. Subjects watched as a treat rolled down an inclined tube into a box. The box either did or did not contain a solid wall dividing it in half. To find the treat, subjects had to modify their search behavior based on the presence or absence of the wall, which either did or did not block the treat's trajectory. Dogs correctly searched the near location when the barrier was present and the far location when the barrier was absent. They displayed this behavior from the first trial, as well as performed correctly when trial types were intermingled. These results suggest that dogs direct their searches in accordance with the solidity principle.
\end{abstract}

Keywords Animal cognition · Solidity · Dog · Animal · Object knowledge

Electronic supplementary material The online version of this article (doi:10.1007/s10071-009-0300-6) contains supplementary material, which is available to authorized users.

S. M. A. Kundey $(\bowtie) \cdot$ C. Taglang $\cdot$ A. Baruch $\cdot$ R. German Department of Psychology, Hood College,

401 Rosemont Avenue, Room RO 27, Frederick,

MD 21701, USA

e-mail: kundey@hood.edu

\section{A. De Los Reyes}

Department of Psychology,

University of Maryland at College Park,

College Park, MD 20742, USA

\section{Introduction}

To survive in their environment, organisms must predict moving objects' trajectories, as well as decide which objects to approach and which to avoid. Making the wrong decision, such as approaching a snake, can often have disastrous consequences. Often, moving objects become hidden from view (e.g., disappear behind a tree). This disappearance is problematic because the organism must maintain a representation of the object in memory, as well as generate an expectation about where it will later appear (Hauser 2001). Humans and a variety of non-human animals (e.g., gorilla—Gorilla gorilla gorilla, Japanese macaque-Macaca fuscata, African Grey parrot-Psittacus erithacus, domesticated dogs-Canis familiaris) can maintain representations of hidden objects over time (e.g., Piaget 1952; Natale et al. 1986; Doré and Dumas 1987; Pepperburg and Funk 1990; Baillargeon and DeVos 1991; Gagnon and Doré 1992; Fiset et al. 2003). However, the factors underlying predictive reaching, searching, and looking for objects that have become hidden from view are not well understood, especially in organisms other than humans and non-human primates.

We commonly assume that organisms use knowledge gleaned from the visual world to direct their behavior within their environment. This assumption is based in large part on research using the expectancy violation paradigm (i.e., "looking-time" method). Within this paradigm, individuals are thought to look longer at events inconsistent with their expectations about the world than those that are consistent. Research using this paradigm indicates that human infants recognize that hidden items continue to exist behind occluders, that objects move in continuous spatiotemporal paths, and that one solid object cannot pass through another (e.g., Baillargeon 1995; Leslie 1994; 
Spelke 1994). Recent research, also employing the expectancy violation paradigm, suggests that adult non-human primates represent objects in much the same way as human infants (e.g., Hauser et al. 1996; Uller et al. 2001; Santos 2004; Santos et al. 2005).

While some work suggests that human infants and some adult non-human primates understand certain object principles when tested in expectancy violation tasks, prior work has also indicated that they often appear unable to use these same principles to successfully locate objects recently hidden from view (e.g., Piaget 1954; Diamond 1991; Munakata et al. 1997; Hauser 2001; Santos and Hauser 2002; Santos 2004). For example, while 4-month-old human children looked longer at an object that appeared to roll through a solid barrier (Spelke et al. 1992), 2-year-old human children did not search in the correct location for an object rolled in the direction of a barrier (e.g., Hood et al. 1999; Butler et al. 2002; Berthier et al. 2000). These studies suggest that when toddlers search for objects, they fail to use the principle of solidity (two solid objects cannot move through one another), which is thought to be understood by 4 months of age (e.g., Spelke et al. 1992). Researchers have observed comparable dissociations between expectancy violation and search paradigms with some adult non-human primates in tasks where subjects are required to reach for objects that undergo interactions with other objects (e.g., Hauser 2001; Hauser et al. 2001; Santos and Hauser 2002; Santos 2004; Santos et al. 2006). In contrast to these results, Cacchione et al. (2009) recently observed that apes successfully utilized solidity and proximity information in conjunction to make correct choices about object movement along horizontal trajectories. However, it is unclear whether apes would have been successful using solidity information alone.

Additional evidence further obfuscates the interpretation of research examining organisms' application of object principles to successfully locate objects hidden from view. For example, neither 2-year-old humans nor adult nonhuman primates are plagued by the problems human infants experience in search tasks. More specifically, by 2 years of age, human children succeed at many means-ends tasks (e.g., Brown 1990), classic tests of inhibition (e.g., Diamond 1991), and possess strong representations of hidden objects (e.g., Munakata etal. 1997). Adult rhesus macaques (Macaca mulatta), one of the species commonly employed in such tasks, possess sophisticated motor capacities, show the capacity to solve tasks involving inhibitory control and working memory (e.g., Diamond 1990, 1993), and show proficiency in tasks involving means-end action sequences with tools (e.g., Hihara et al. 2003).

Many questions remain about why dissociations emerge between search and expectancy violation tasks, as well as what they mean. Various interpretations of why such mismatches occur have been posited (e.g., Gómez 2005). For example, one interpretation holds that such mismatches emerge due to lack of executive ability (e.g., Gómez 2005). This account suggests that as executive ability develops, behavior should become more consistent across looking and motor tasks (e.g., Diamond 1991). In human children, such mismatches between knowing and acting can be viewed within a developmental framework that incorporates maturation of the systems underlying executive control (e.g., Gómez 2005). However, this mismatch does not appear to resolve in adult non-human primates in the same manner that it does in humans. A second hypothesis holds that the knowledge gleaned through looking-time methods is not the same knowledge used for successful action in motor search tasks (e.g., Munakata 2001; Bogartz et al. 2000; Gómez 2005). More specifically, Munakata (2001) hypothesized that looking-time and manual search reflect different representations. Whereas looking-time data reflect 'weak' object representations, successful motor searches require 'stronger' object representations (Munakata 2001). Accordingly, it is possible that some species develop only weak representations while others eventually develop strong representations within the same domain, reflecting differential success across looking-time and motor search tasks. Finally, other theorists argue that the global interplay among cognitive subsystems must be considered (e.g., Smith and Thelen 2003). Across species, cognitive abilities such as object permanence or understanding of solidity might develop in differing cognitive contexts among species.

Although questions linger regarding the nature and interpretation of dissociations between search and expectancy violation tasks, we have learned much in recent years regarding how human infants and non-human primates represent objects. Studies have also begun to reveal how other species represent objects (e.g., Pepperberg and Kozak 1986; Goulet et al. 1994; Funk 1996; Pepperberg et al. 1997; Pollock et al. 2000; Cooper et al. 2003; Fiset et al. 2003, 2006, 2007; Collier-Baker et al. 2004; Mendes and Huber 2004; Fiset and Doré 2006; Zucca et al. 2007; Miklósi 2007; Miller et al. 2009; Whitt et al. 2009; Deppe et al. 2009). Indeed, such explorations could provide new insights into tasks with human and non-human primate populations. More specifically, investigations employing a species not traditionally examined in this research such as dogs might offer information regarding interactions of naïve knowledge of solidity and learned behavior, as well as whether species-specific mechanisms exist.

Domesticated dogs likely utilize representations of objects in their everyday life for such tasks as searching and retrieving objects. Yet, we largely lack information to judge how similar or different their representations are from our own. Researchers have begun to explore dogs' knowledge 
of objects in a variety of ways. For example, several past studies successfully excluding the role of olfactory cues have demonstrated that dogs can succeed at invisible displacement problems (e.g., Triana and Pasnak 1981; Gagnon and Doré 1992, 1993; Watson et al. 2001; but see CollierBaker et al. 2004; Fiset and LeBlanc 2007). Additionally, dogs do show an initial gravity bias, and yet they (unlike human infants and monkeys) are able to learn to overcome their gravity bias (Osthaus et al. 2003).

Here, we sought to assess dogs' knowledge of solidity by evaluating search behavior when an object rolled in the direction of a barrier. We chose to study solidity because past research indicates that human toddlers, adult rhesus macaques, and adult cotton-top tamarins (Saguinus oedipus) all fail to reason about the location of a hidden barrier when reaching for an invisibly displaced object even though they show sensitivity to solidity information in expectancy violation paradigms (Spelke et al. 1992; Berthier et al. 2000; Hood et al. 1999; Santos 2004; Santos et al. 2006).

\section{Methods}

\section{Subjects}

The study was performed in the mid-Atlantic region of the US in 2009. The owners and their dogs were recruited through personal contact with the laboratory staff or via fliers posted throughout the community. Participation in tests was voluntary and limited to dogs over 1 year of age. Dogs included in this study had not had any formal agility or advanced obedience training. They were also reported by their owner to be free from major health problems. Laboratory staff pointed out to the owners that there were no correct or incorrect behaviors and that during the tasks they were not to help their dog in any way.
As described later, before exposure to the experimental trials, dogs completed pretraining to ensure that they could and would make choices freely from both sides of the apparatus without owner direction. The ten dogs ( $M=4.5$ years, $\mathrm{SD}=2.6$, four female and six males $)$ that successfully completed this pretraining were included in the study. One dog was excluded due to failure to make choices during pretraining, and one dog was excluded due to a side bias (only choosing from one side of the apparatus) during pretraining. The breed composition of our sample (as reported by the owners) included one pug, one Australian shepherd, one Catahoula, one golden retriever, and six dogs of mixed breeds. Our sample size of ten dogs falls within the wide range of sample sizes often employed by others exploring dogs' cognitive abilities (e.g., Topál et al. 2006; Osthaus et al. 2005; Fiset et al. 2003; Miklósi et al. 1998).

\section{Apparatus}

Figure 1 depicts the apparatus. It consisted of a clear plastic tube ( $1 \mathrm{~m}$ in length, $3.5 \mathrm{~cm}$ in diameter), which extended diagonally into a wooden box $(50 \mathrm{~cm} \times 25 \mathrm{~cm} \times 10 \mathrm{~cm})$. We placed white adhesive tape along the rear exterior of the tube to aid subjects in seeing the movement of a brown dog treat $(2 \mathrm{~cm}$ in diameter) down the length of the tube. The front exterior of the tube remained clear. Thus, when the dog looked through the clear front of the tube, they saw the brown treat sliding against a white background.

The tube was positioned such that it rose $0.75 \mathrm{~m}$ off the ground at its highest extent and entered the wooden box at $12 \mathrm{~cm}$ off the ground. The wooden box could be opened and closed via a hinged front panel. The hinged panel contained two doors $(12 \mathrm{~cm} \times 12 \mathrm{~cm})$ centered on either side of the front panel to allow easy access to either half of the box. The doors were covered with multiple layers of fabric to prevent subjects from viewing the inside of the box.
Fig. 1 Line drawing of the apparatus used in the experiment. The solid wall is shown in the inserted position

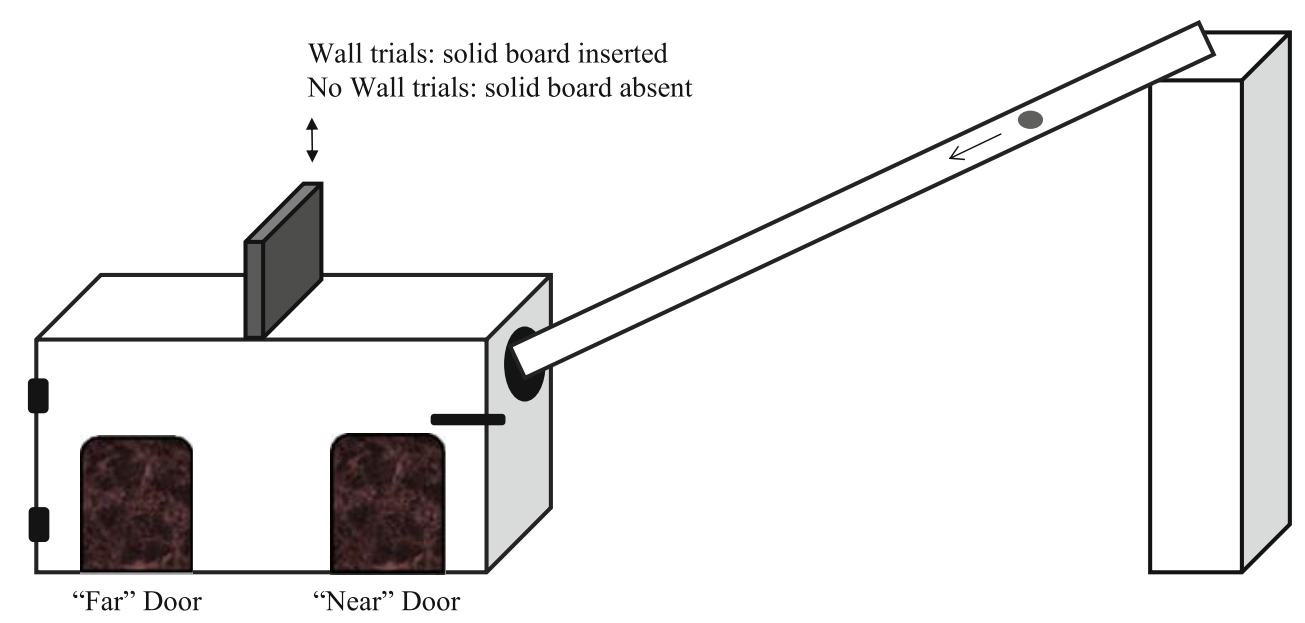


However, subjects could easily reach inside the openings to access the box's interior with either their snout or paw.

The rear wall of the box consisted of a false back, which allowed the experimenter to control the placement of treats. The top of the box contained a slit, which allowed the experimenter to slide a solid black barrier $(38 \mathrm{~cm} \times$ $25 \mathrm{~cm} \times 0.5 \mathrm{~cm}$ ) into the box. We reasoned if subjects understood that the solid barrier blocked the treat's trajectory, they should use the position of the barrier to ascertain the fallen treat's location behind one of the two doors when making choices. The box was false-baited throughout test trials to control for possible use of olfactory cues.

False-baiting was accomplished while the dog was briefly distracted. The owner was instructed prior to the start of the experiment that upon request, they would need to direct their dog's attention away from the apparatus. With small dogs, the owner often physically lifted and held their dog such that it faced away from the apparatus. With larger dogs, the owner covered the dogs' eyes or held the dog's face such that they could not see the apparatus. During test trials, the experimenter ensured each compartment contained one treat when the dog made a choice. The falsebaited treat was placed while the dog was distracted. This procedure is described more fully below. The inside floor of the box was also frequently rubbed with dog treats. Auditory cues related to the treats' falls were similar across trials and muffled by the box.

\section{Procedure}

All procedures were approved by the institution's Animal Care and Use Committee. Testing occurred in a room within the laboratory. The dog's owner was present throughout all testing sessions and remained behind their dog, maintaining control over the subject's leash.

First, dogs were allowed to become familiar with the experimenters, the test apparatus, and their general surroundings by exploring the general area unhindered while their owner completed various forms regarding such domains as the dog's general health, disposition, and training. This familiarity period was of $\sim 10$ min duration. Following this acclimation period, all dogs underwent pretraining.

\section{Pretraining trials}

The goal of pretraining was to further accustom the dog to the apparatus, as well as ensure that the dog would make choices in the absence of owner direction. We permitted the owner to make short general commands to stay, sit, and release. During pretraining, the owner held the dog at a distance of approximately $1 \mathrm{~m}$ from the apparatus, centered in front of the wooden box. During all pretraining trials, dogs were only allowed to make one choice per trial. The experimenter was positioned behind the apparatus with the hinged front panel initially open. She showed a treat to the dog, and, as the dog watched, she placed the treat inside the box in one of two locations (counterbalanced across subjects) using the front opening: near (the half of the box closest to where the tube entered) or far (the half of the box farthest from where the tube entered). After placing the treat, the experimenter instructed the owner to release the dog, so that it could come forward to retrieve the treat. After instructing the owner, the experimenter immediately looked away from the box and refrained from making eye contact with the dog or owner to avoid giving the subject any nonverbal cues. This was repeated for the remaining side of the box (near or far).

Next, the experimenter closed the box's front panel. The experimenter repeated the procedure above with the exception that she reached through the appropriate curtain on the front panel to place each treat, and three trials were conducted with each half of the box (counterbalanced across subjects).

Dogs that failed to choose without owner direction or that displayed a side bias during pretraining were excluded from the remaining trials $(n=2)$. Dogs were considered to have a side bias during pretraining if they only made choices from one door throughout pretraining. Excluded subjects were not included in the subsequent data analysis and did not engage in any test trials. Dogs that successfully completed pretraining moved on to the experimental phase.

\section{Test trials}

Two types of test trials were conducted: "No Wall" and "Wall". Trials were run in three blocks: "No Wall", "Wall," and "Mixed". Wall and No Wall blocks consisted of six trials each. Only No Wall trials were conducted in the No Wall block; similarly, only Wall trials were conducted in the Wall block. During the Mixed block, three No Wall and three Wall trials were conducted for a total of six trials; trial order was counterbalanced across subjects and occurred in a pseudorandom sequence. No more than two trials of the same trial type could appear in succession in the Mixed block. The block order of the No Wall and Wall trials was counterbalanced across subjects; however, the Mixed block always appeared last. Videotaped examples of Wall and No Wall trials, as described later, can be found in the online supplementary information.

In the No Wall trials, the solid barrier was not present to separate the box's halves. The experimenter first demonstrated that the box was empty by opening the front of the box. She said "look" and the dog's name while passing her hand through the center of the open box. Dogs were allowed to sniff the inside of the box. Then, she closed the 
box's front door. While the dog and owner were briefly distracted, the experimenter secretly placed a treat on the near side of the apparatus. Next, the experimenter gained the dog's attention by saying its name and "look" to direct it to look at a second treat in her hand above the hole in the tube. She then dropped the treat into the tube. The treat landed and was contained within the far compartment. Importantly, after the treat was dropped into the tube, the experimenter did not interfere with the box prior to the dog making a choice. Depending on the size and demeanor of the dog, she stood (big or very excited dogs) or sat (small or tentative dogs) behind the box such that she was centered between the two openings. She avoided both eye contact with the dog and owner, as well as looking at the box by either looking at her feet (if standing) or her lap (if sitting).

The dog was then allowed to make a choice between the doors on the front panel. If the dog chose correctly (i.e., the far door), it was allowed to consume the treat. If the dog chose incorrectly (i.e., the near door), the treat was removed from the far door such that the dog could see it. When incorrect choices were made, the dog was not allowed to consume the treat from either the correct or incorrect location.

At the beginning of the block of Wall trials, the experimenter opened the box's hinged front opening. She said "look" and the dog's name to gain the dog's attention. She tapped each side of the solid barrier and then placed it within the wooden box. After placing the solid barrier within the wooden box, she tapped it again. Dogs were allowed to sniff the inside of the box and the solid barrier. Then, she closed the box's front door. For each trial within this block, the experimenter surreptitiously preloaded the box with a treat on the far side of the apparatus while the dog and owner were distracted. Next, the experimenter gained the dog's attention by saying its name and saying "look" to direct it to look at a second treat in her hand above the hole in the tube. She then dropped the treat into the tube. The treat landed and was contained within the near compartment and the dog was allowed to make a choice in a similar manner to No Wall trials. The dog was then allowed to make a choice between the doors on the front panel. If the dog chose correctly (i.e., the near door), it was allowed to eat the treat. If the dog chose incorrectly (i.e., the far door), the treat was removed from the near door such that the dog could see it. However, in this case, the dog was not allowed to consume the treat.

During the Mixed block, three Wall and three No Wall trials were completed in the same manner as described previously. For Wall trials, the experimenter demonstrated that the barrier was solid in the manner indicated earlier each time it was inserted.
Data collection and analysis

A second experimenter recorded the first door the dog searched within each trial. Responses were counted as correct only when the dog touched the curtain in front of the fallen treat with any part of its face or forepaws first (i.e., the near door for Wall trials and the far door for No Wall trials). Dogs were only permitted to make one choice per trial. In the case of incorrect searches, the dog was not allowed to search again. The treat was removed from the correct door, shown to the dog, and the dog was taken back to the starting position by its owner.

Choices were confirmed via later videotape analysis by two naïve coders. Agreement among coders was high (Cohen's $\kappa=0.93$ for all trials). We converted the number of correct searches made by the dog into a percentage of correct searches for each trial type within each block.

We utilized one-sample $t$-tests to determine whether dogs' mean performance differed from that expected by chance. We compared dogs' percentage of correct choices in each trial type to a chance value of $50.0 \%$ because there were two places in which the dogs could search. If dogs were searching at chance, we would expect them to only choose the correct side on $50.0 \%$ of trials. We also employed paired-samples $t$-tests to determine whether performance differed between trial types. Finally, we used binomial tests to determine whether dogs chose the correct location significantly above chance on the first trial of each trial type. In all tests, results were only considered significant if alpha $<0.05$.

\section{Results}

The data from each condition are depicted in Fig. 2. The number of dogs committing different numbers of search errors for each of the three conditions is reported in

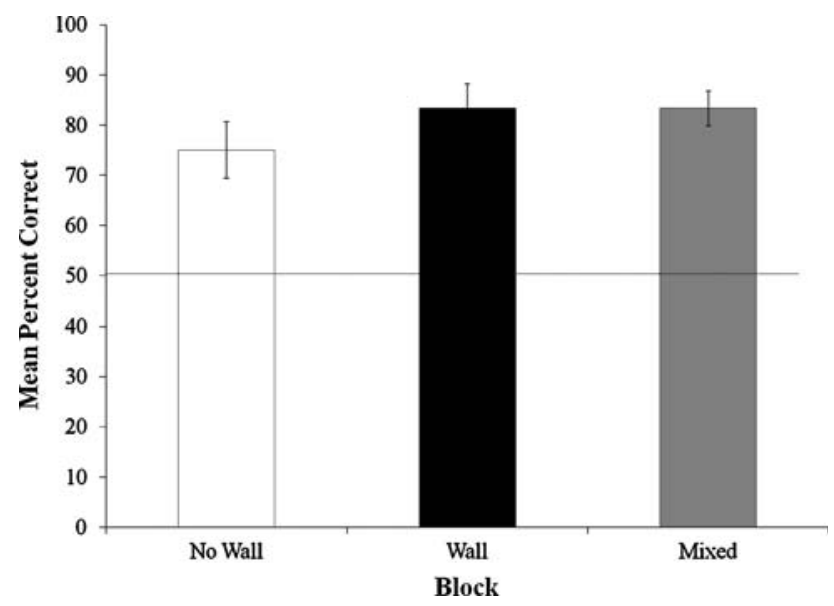

Fig. 2 Mean percent correct during each block of trials: No Wall, Wall, and Mixed. Chance is $50.0 \%$. Error bars represent SEM 
Table 1 Number of dogs in each condition committing different numbers of search errors

\begin{tabular}{llllllll}
\hline Condition & \multicolumn{6}{l}{ Number of errors } \\
\cline { 2 - 7 } & 0 & 1 & 2 & 3 & 4 & 5 & 6 \\
\hline No Wall & 2 & 4 & 2 & 2 & 0 & 0 & 0 \\
Wall & 3 & 5 & 2 & 0 & 0 & 0 & 0 \\
Mixed & 2 & 6 & 2 & 0 & 0 & 0 & 0 \\
\hline
\end{tabular}

Digits reflect the number of dogs in each of the different conditions (Wall, No Wall, and Mixed trials) committing different numbers of search errors (searching at the non-baited location)

Table 1. We first employed one-sample $t$-tests to determine if dogs searched in the correct half of the box for each of the first two blocks. During these blocks, dogs received a block of six No Wall trials and a block of six Wall trials. In the No Wall condition, dogs searched in the correct far location on $77.0 \%$ (SEM $=5.69)$ of the trials. The one-sample $t$-test indicated dogs searched in the far location significantly above chance in the No Wall trials, $t_{9}=4.39$, $P=0.02(d=1.38$, power $=0.95)$. In the Wall condition, dogs searched in the correct near location on $85.0 \%$ (SEM $=4.96)$ of trials. We again compared dogs' performance to a chance value of $50.0 \%$ using a one-sample $t$ test. The test indicated dogs searched in the near location significantly above chance during Wall trials, $t_{9}=6.71$, $P<0.001(d=2.12$, power $=0.98)$.

Next, we compared performance between the blocks of Wall and No Wall trials to determine if a difference in accuracy existed using a paired-samples $t$-test. The test indicated no difference in accuracy between the two trial types, $t_{9}=0.958, P=0.63(d=0.30)$.

Although subjects only completed six No Wall and six Wall trials within these first two blocks, we were concerned that perhaps dogs had learned the correct response (i.e., respond to the near locations for the Wall trials and the far location for the No Wall trials) over the course of the repeated trials they experienced. To test this explanation, we evaluated subjects' responses for the first trial of each of the No Wall and Wall conditions by employing a binomial test. For the No Wall trials, all ten subjects selected the appropriate side of the box (far) on the first trial, $P<0.001$. For the Wall trials, nine of ten subjects selected the appropriate side of the box (near, respectively) on the first trial, $P=0.02$. Given that dogs performed accurately from the first trial of each trial type, a learning explanation for dogs' accurate performance over trials is unlikely.

Finally, we examined dogs' performance during the Mixed block of trials. In this section, subjects experienced both No Wall and Wall trials intermixed in a pseudorandom sequence. The mean percentage of correct choices in this block was $83.3 \%$ (SEM $=3.51)$. We again compared dogs' performance to a chance value of $50.0 \%$ using a one-sample $t$-test. The test indicated dogs searched in the correct location (near or far, depending on the presence or absence of the barrier) significantly above chance, $t_{9}=9.49$, $P<0.001(d=2.99$, power $=0.97)$. This suggests that dogs were able to correctly modify their search behavior depending on the presence or absence of the barrier. We also compared performance for the Wall and No Wall trials within the Mixed block to determine if a difference in accuracy existed using a paired-samples $t$-test. The test indicated no difference in accuracy between the two trial types, $t_{9}=0.51$, $P=0.62 \quad(d=0.16)$. This suggests that subjects were equally adept at determining the location of the treat both with and without the solid barrier in place during the Mixed block.

Overall, dogs correctly searched the near location when the barrier was present in Wall trials and the far location when the barrier was absent in No Wall trials. Dogs spontaneously searched in the correct location from the first trial of each trial type (Wall and No Wall), as well as performed correctly when the trial types were intermingled during the Mixed block. Collectively, the data suggest that dogs search in accordance with the principle of solidity, understanding that one solid object cannot pass through another.

\section{Control trials}

Given the surprising nature of these findings, we examined whether subtle cuing during the experimental trials or during pretraining might underlie dogs' performance. Specifically, six $\operatorname{dogs}(M=4.2$ years, $\mathrm{SD}=3.1$, two female and four males) participated in a control condition. The breed composition of the dogs included in the control trials (as reported by their owner) were three Australian shepherds, one German short-haired pointer, and two dogs of mixed breeds).

We conducted the pretraining and experimental (six Wall trials, six No Wall trials, six Mixed trials) trials in the same manner as described earlier with two exceptions: (1) a treat was not dropped down the tube and (2) both the near and far sides of the box were false-baited while the dog was distracted. If dogs in the experimental trials were simply making choices based on the gestures or subtle cues given by the experimenter, the motion of the treat should not matter in dogs' choices and we should observe similar results to those reported when the treat was rolled down the tube. Thus, in the control trials if dogs were detecting and acting in accordance with subtle experimenter cuing, we hypothesized that the dogs would consistently choose the near door for Wall trials and the far door for No Wall trials. If, however, the motion of the treat mattered to dogs' choices, we 
expected dogs' performance to be at chance levels when the treat was not dropped through the tube.

On No Wall trials, dogs chose the far side of the box on $55 \%$ of trials. This was not significantly different from chance using a one-sample $t$-test $\left(t_{5}=0.44, P=0.68\right)$. On Wall trials, dogs chose the near side of the box on $61 \%$ of trials. This was also not significantly different from chance using a one-sample $t$-test $\left(t_{5}=0.88, P=0.42\right)$. During Mixed trials, dogs chose correctly on $42 \%$ of trials. This was also not significantly different from chance using a one-sample $t$-test $\left(t_{5}=-1.17, P=0.29\right)$.

Together, the data suggest that dogs did not readily choose correctly when the treat's motion was removed in Wall and No Wall trials. These results address the possibility that the experimenter was subtly cuing the dogs in experimental trials.

\section{Discussion}

In conjunction, the data suggest that dogs understand and can use the principle of solidity - that one solid object cannot pass through another solid object-to determine the location of a hidden treat. Importantly, they readily use this information in search tasks from the first trial. This outcome differs from past research with human toddlers, adult rhesus macaques, and adult cotton-top tamarins (Saguinus oedipus). These subjects all failed to reason about the location of a hidden barrier when reaching for an invisibly displaced object, but evidenced sensitivity to solidity information in expectancy violation paradigms (Spelke et al. 1992; Berthier et al. 2000; Hood et al. 1999; Santos 2004; Santos et al. 2006). Our results, however, do accord with the findings of Cacchione et al. (2009) indicating that apes act in accordance with solidity and proximity information in conjunction in tasks requiring judgments regarding object movement in horizontal trajectories. Additionally, these results suggest that dogs in this paradigm understood invisible displacement. That is, they successfully located a treat that moved away from the bottom of the tube after falling from it toward the far end of the box. Although some studies suggest that dogs do not understand invisible displacement problems (CollierBaker et al. 2004; Fiset and LeBlanc 2007), a number of other studies suggest that they do understand these problems (e.g., Triana and Pasnak 1981; Gagnon and Doré 1992, 1993; Watson et al. 2001). Perhaps dogs understand invisible displacement when it is achieved via gravity or self-propelled motion but not if it is brought about through the manipulations of human actors in a more artificial manner.

Why do dogs appear to utilize solidity information in search tasks while young humans and adult non-human primates do not do so consistently? The mechanism underlying dogs' success in this task is unclear, although prior work may yield insights to guide future research. First, perhaps dogs come into the world with an innate understanding of objects and how they interact, reminiscent of Spelke et al.'s (1992) core knowledge proposal for human infants. To date, few developmental studies with canines have evaluated what knowledge dogs do and do not have about objects. Second, it is also possible that dogs learned over their lifetime how objects interact, including the principle of solidity. While the current data do not appear attributable to learning within the trials of this task, it is possible that the experiences dogs brought with them to the experimental situation through interactions with objects gained over their lifetime gave rise to accurate performance. Third, perhaps humans influence dogs' ability to use solidity information. That is, humans utilize solidity information in their everyday interactions with objects. A variety of studies have indicated that dogs are proficient readers of human attention and gestures (e.g., Miklósi et al. 1998; Hare et al. 1998; Agnetta et al. 2000; Soproni et al. 2001, 2002; Cooper et al. 2003). All of the subjects employed in our study lived with humans. Perhaps these dogs learned to pay attention to solidity information through attending to their owners' interactions with objects over time. That is, perhaps their owner's gestures cued dogs to the importance of solidity in interactions with objects. Fourth, it is also possible that domestication played a role in the emergence of dogs' abilities to understand and use solidity information. That is, during domestication and breed selection, some individuals may have been selected-whether implicitly or explicitly - for their ability to understand how objects interact (Coppinger and Coppinger 2001). Such skills would no doubt be valuable to breeds assisting humans in hunting and service (e.g., cattle cannot be herded through a solid fence). Dissociating such explanations may be accomplished through future experiments that compare domesticated dogs and undomesticated wolves (Canis lupis), dogs with different levels of socialization to humans, as well as the performance of adult and juvenile animals.

The experiment presented here clearly does not completely resolve or explain the discrepancies often seen between the findings of studies examining performance in infant looking and reaching tasks. However, our findings contribute to a more inclusive investigation of physical knowledge across primate and non-primate species. Comparison across species, tasks, and development will likely provide a more complete understanding of the principles governing search behavior, looking, and underlying object representations. As such, future research may be better positioned to render evidence addressing these critical issues within the cognitive development field. 
Acknowledgments Shannon M. A. Kundey, Chelsea Taglang, Ayelet Baruch, and Rebecca German, Department of Psychology, Hood College; Andres De Los Reyes, Comprehensive Assessment and Intervention Program, Department of Psychology, University of Maryland at College Park. We would like to thank Jessica Arbuthnot, Rebecca Allen, Ariel Coshun, Erica Royer, Sherry McClurkin, Sabrina Molina, and Robin Reutten for their assistance in data collection and participant recruitment for this study.

\section{References}

Agnetta B, Hare B, Tomasello M (2000) Cues to food locations that domestic dogs (Canis familiaris) of different ages do and do not use. Anim Cogn 3:107-112

Baillargeon R (1995) Physical reasoning in infancy. In: Gazzaniga M (ed) The cognitive neurosciences. MIT, Cambridge, pp 181-204

Baillargeon R, DeVos J (1991) Object permanence in young infants: further evidence. Child Dev 62:1227-1246

Berthier N, Deblois S, Poirier CR, Novak MA, Clifton RK (2000) Where's the ball? Two and three year olds reason about unseen events. Dev Psychol 26:394-401

Bogartz R, Shinskey J, Schilling T (2000) Object permanence in fiveand-a half-month-old infants? Infancy 1:403-428

Brown A (1990) Domain-specific principles affecting learning and transfer in children. Cogn Sci 14:107-133

Butler S, Berthier N, Clifton R (2002) Two-year-olds' search strategies and visual tracking in a hidden displacement task. Dev Psychol 38:581-590

Cacchione T, Call J, Zingg R (2009) Gravity and solidity in four great ape species (Gorilla gorilla, Pongo pygmaeus, Pan troglodytes, Pan paniscus): vertical and horizontal variations of the table task. J Comp Psychol 123:168-180

Collier-Baker E, Davis J, Suddendorf T (2004) Do dogs (Canis familiaris) understand invisible displacement? J Comp Psychol 118:421-433

Cooper JJ, Ashton C, Bishop S, West R, Mills DS, Young RJ (2003) Clever hounds: social cognition in the domestic dog (Canis familiaris). Appl Anim Behav Sci 81:229-244

Coppinger RP, Coppinger L (2001) Dogs: a new understanding of canine origin, behavior, and evolution. University of Chicago Press, Chicago

Deppe A, Wright P, Szelistowski W (2009) Object permanence in lemurs. Anim Cogn 12:381-388

Diamond A (1990) Developmental time course in human infants and infant monkeys, and the neural basis of the inhibitory control of reaching. In: Diamond A (ed) The development and neural bases of higher cognitive functions. New York Academy of Sciences, New York, pp 637-676

Diamond A (1991) Neuropsychological insights into the meaning of object concept development. In: Carey S, Gelman R (eds) The epigenesis of mind: essays on biology and cognition. Erlbaum, New Jersey, pp 67-110

Diamond A (1993) Neuropsychological insights into the meaning of object concept development. In: Johnson MH (ed) Brain development and cognition: a reader. Blackwell, Malden, pp 208-247

Doré FY, Dumas C (1987) Psychology of animal cognition: Piagetian studies. Psychol Bull 102:219-233

Fiset S, Doré F (2006) Duration of cats' (Felis catus) working memory for disappearing objects. Anim Cogn 9:62-70

Fiset S, LeBlanc V (2007) Invisible displacement understanding in domestic dogs (Canis familiaris): the role of visual cues in search behavior. Anim Cogn 10:211-224

Fiset S, Beaulieu C, Landry F (2003) Duration of dogs' (Canis familiaris) working memory in search for disappearing objects. Anim Cogn 6:1-10
Fiset S, Landry F, Ouellette M (2006) Egocentric search for disappearing objects in domestic dogs: evidence for a geometric hypothesis of direction. Anim Cogn 9:1-12

Fiset S, Beaulieu C, LeBlanc V, Dubé L (2007) Spatial memory of domestic dogs (Canis familiaris) for hidden objects in a detour task. J Exp Psychol Anim Behav Process 33:497-508

Funk M (1996) Development of object permanence in the New Zealand parakeet (Cyanoramphus auriceps). Anim Learn Behav 24:375-383

Gagnon S, Doré FY (1992) Search behavior in various breeds of adult dogs (Canis familiaris): object permanence and olfactory cues. J Comp Psychol 106:58-68

Gagnon S, Doré FY (1993) Search behavior of dogs (Canis familiaris) in invisible displacement problems. Anim Learn Behav 21:246254

Gómez J (2005) Species comparative studies and cognitive development. Trends Cogn Sci 9:118-125

Goulet S, Doré F, Rousseau R (1994) Object permanence and working memory in cats (Felis catus). J Exp Psychol Anim Behav Process 20:347-365

Hare B, Call J, Tomasello M (1998) Communication of food location between human and dog (Canis familiaris). Evol Commun 2:137-159

Hauser MD (2001) Searching for food in the wild: a nonhuman primate's expectations about invisible displacement. Dev Sci 4:8493

Hauser MD, MacNeilage P, Ware M (1996) Numerical representations in primates. Proc Natl Acad Sci 93:1514-1517

Hauser MD, Williams T, Kralik JD, Moskovitz D (2001) What guides a search for food that has disappeared? Experiments on cotton-top tamarins (Saguinus oedipus). J Comp Psychol 115:140-151

Hihara S, Obayashi S, Tanaka M, Iriki A (2003) Rapid learning of sequential tool use by macaque monkeys. Phys Behav 78:427-434

Hood BM, Hauser MD, Anderson L, Santos L (1999) Gravity biases in a nonhuman primate? Dev Sci 2:35-41

Leslie AM (1994) ToMM, ToBy, and agency: core architecture and domain specificity. In: Hirschfield LA, Gelman SA (eds) Mapping the mind: domain specificity in cognition and culture. Cambridge University Press, Cambridge

Mendes N, Huber L (2004) Object permanence in common marmosets (Callithrix jacchus). J Comp Psychol 118:103-112

Miklósi Á (2007) Dog behaviour, evolution, and cognition. Oxford University Press, Oxford

Miklósi Á, Polgárdi R, Topál J, Csányi V (1998) Use of experimentergiven cues in dogs. Anim Cogn 1:113-121

Miller HC, Gipson CD, Vaughan A, Rayburn-Reeves R, Zentall T (2009a) Object permanence in dogs: invisible displacement in a rotation task. Psychon Bull Rev 16:150-155

Miller HC, Rayburn-Reeves R, Zentall T (2009b) What do dogs know about hidden objects? Behav Process 81:439-446

Munakata Y (2001) Graded representations in behavioral dissociations. Trend Cogn Sci 5:309-315

Munakata Y, McClelland JL, Johnson MH, Siegler RS (1997) Rethinking infant knowledge: toward an adaptive processing account of successes and failures in object permanence tasks. Psychol Rev 104:686-713

Natale F, Antinucci F, Spinozzi G, Poti P (1986) Stage 6 object concept in nonhuman primate cognition: a comparison between gorilla (Gorilla gorilla gorilla) and Japanese macaque (Macaca fuscata). J Comp Psychol 100:335-339

Osthaus B, Slater A, Lea SEG (2003) Can dogs defy gravity? A comparison with the human infant and a non-human primate. Dev Sci 6:249-489

Osthaus B, Lea SEG, Slater AM (2005) Dogs (Canis lupis familiaris) fail to show understanding of means end connections in a string pulling task. Anim Cogn 8:37-47 
Pepperberg I, Kozak F (1986) Object permanence in the African Grey parrot (Psittacus erithacus). Anim Learn Behav 14:322-330

Pepperberg I, Willner M, Gravitz L (1997) Development of Piagetian object permanence in grey parrot (Psittacus erithacus). J Comp Psychol 111:63-75

Pepperburg IM, Funk FA (1990) Object permanence in four species of psittacine birds: an African Grey Parrot (Psittacus erithacus), an Illiger mini macaq (Ara maracana), a parakeet (Melopsittacus undulates), and a cockatiel (Nymphicus hollandicus). Anim Learn Behav 14:322-330

Piaget J (1952) The origins of intelligence in children. International University Press, New York

Piaget J (1954) The construction of reality in the child. Basic Books, New York

Pollock B, Prior H, Güntürkün O (2000) Development of object permanence in food-storing magpies (Pica pica). J Comp Psychol 114:148-157

Santos LR (2004) 'Core knowledges': A dissociation between spatiotemporal knowledge and contact-mechanics in a nonhuman primate? Dev Sci 7:167-174

Santos LR, Hauser MD (2002) Monkey see versus monkey do?: dissociations between looking and action in a non-human primate. Dev Sci 5:F1-F7

Santos LR, Mahajan N, Barnes JL (2005) How prosimian primates represent tools: experiments with two lemur species (Eulemur fulvus and Lemur catta). J Comp Psychol 119:394-403

Santos LR, Seelig D, Hauser MD (2006) Cotton-top tamarins' (Saguinus oedipus) expectations about occluded objects: a dissociation between looking and reaching tasks. Infancy 9:147-171
Smith L, Thelen E (2003) Development as a dynamic system. Trend Cogn Sci 7:343-348

Soproni K, Miklósi Á, Topál J, Csányi V (2001) Comprehension of human communicative signs in pet dogs. J Comp Psychol 115:122-126

Soproni K, Miklósi Á, Topál J, Csányi V (2002) Dogs' (Canis familiaris) responsiveness to human pointing gestures. J Comp Psychol 116:27-34

Spelke ES (1994) Initial knowledge: six suggestions. Cognition 50:431-445

Spelke ES, Breinlinger K, Macomber J, Jacobson K (1992) Origins of knowledge. Psychol Rev 99:605-632

Topál J, Byrne R, Miklósi A, Csányi V (2006) Reproducing human actions and action sequences: "Do as I do!" in a dog. Anim Cogn 9:355-367

Triana E, Pasnak R (1981) Object permanence in cats and dogs. Anim Learn Behav 9:135-139

Uller C, Hauser J, Carey S (2001) Spontaneous representation of number in cotton-top tamarins (Saguinus oedipus). J Comp Psychol 115:248-257

Watson JS, Gergely G, Topál J, Gácsi M, Sárközi ZS, Csányi V (2001) Distinguishing logic versus association in the solution of an invisible displacement task by children and dogs: using negation of disjunction. J Comp Psychol 115:219-226

Whitt E, Douglas M, Osthaus B, Hocking I (2009) Domestic cats (Felis catus) do not show causal understanding in a string-pulling task. Anim Cogn 12:739-743

Zucca P, Milos N, Vallortigara G (2007) Piagetian object permanence and its development in Eurasian Jays (Garrulus glandarius). Anim Cogn 10:243-258 